Cuadernos de Pensamiento $\mathrm{N}^{\circ} 33$

Número monográfico sobre Karol Wojtyla/san Juan Pablo II en el centenario de su nacimiento. Volumen 2.

Año: 2020

DOI: https://doi.org/10.51743/cpe.63

tren ivenese

anctestwoec

PLLAR Iraran

arhevezuscour

vovel reancis

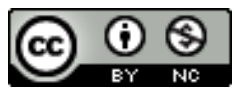

NARDaGarar

\title{
¿Quién fue Karol Józef Wojtyla?
}

\section{Who Was Karol Józef Wojtyla?}

\author{
JosÉ LuIS ORELLA MARTÍNEZ \\ Universidad CEU San Pablo
}

Resumen: Este año es el centenario del nacimiento de san Juan Pablo II, un Papa con una extraordinaria capacidad de llegar a la gente. El mundo conoce su pensamiento y sus numerosos viajes, pero es necesario saber quién fue Karol Wojtyla. El joven polaco que nació a la vez que su país recuperaba su soberanía, afrontará junto a su nación, las dos mayores experiencias totalitarias y la Segunda Guerra Mundial. Hechos que le marcaron y prepararon para ser el papa del nuevo milenio. A través de este artículo, pretendo descubrir como el contexto cultural e histórico que vivió en Polonia, fueron cincelando la personalidad del futuro pontífice. Las personas que conoció le irán aportando el conocimiento que necesitará en el futuro. Su amor por la cultura a través de la poesía y el teatro, la mística de los autores españoles, el mundo del trabajo, el ejemplo de su familia, la entrega sacerdotal... Todos fueron aportando a su sensibilidad y conocimiento, con el mundo intelectual, la santificación del trabajo, el apostolado de la juventud y la entrega del laico.

Palabras Clave: Karol Wojtyla, Iglesia católica, guerra fría, comunismo, Concilio Vaticano II, apostolado

ABSTRACT: This year is the centenary of the birth of Saint John Paul II, a Pope with an extraordinary ability to reach people. The world knows his thoughts and his numerous trips, but it is necessary to know who Karol Wojtyla was? The young Pole 
who was born while his country regained its sovereignty, he will face, together with his nation, the two greatest totalitarian experiences and the Second World War. Facts that marked and prepared him to be the pope of the new millennium. Through this article, I intend to discover how the cultural and historical context that lived in Poland, were carving the personality of the future pontiff. The people he met would provide him with the knowledge he would need in the future. His love for culture through poetry and theater, the mystique of Spanish authors, the world of work, the example of his family, the dedication of the priesthood... All of them contributed to his sensitivity and knowledge, with the intellectual world, the sanctification of work, the apostolate of youth and the dedication of the laity.

KEYwords: Karol Wojtyla, Catholic Church, Cold War, Communism, Second Vatican Council, Apostolate

$E^{1}$ 16 de octubre de 1978 el arzobispo de Cracovia, cardenal Karol Wojtyła era proclamado Papa de la Iglesia Católica. Aquel fue un hecho histórico que daba a la Iglesia del Silencio, la que sobrevivía bajo el dominio del mundo comunista, una relevancia internacional. Posteriormente, bajo su pontificado, Juan Pablo II fue revelándose como una persona excepcional por la fuerza de su espíritu y carácter. En el centenario de su nacimiento daremos unas claves para entender como pudo forjarse un hombre tan excepcional para preparar a la Iglesia para el nuevo milenio.

\section{LA POLONIA DE SU NIÑEZ}

Polonia renace un 11 de septiembre de 1918, después del fin de los imperios tras la Primera Guerra Mundial. El primer objetivo será el difícil engarce de aquellas provincias, con costumbres tan diferentes, después de 123 años de separación, y la defensa de las nuevas fronteras del nuevo Estado. Józef Piłsudski el nuevo Jefe de Estado y el compositor Ignazy Paderewski, como flamante primer ministro, se encontraron al frente de un país por reconstruir. A principios de 1920 será Wincenty Witos, líder del partido Campesino, el nuevo primer ministro. En la Polonia de aquel momento, el abanico político 
se fue concretando en tres amplios espacios: el Polska Partia Socjalistyczna (Partido Socialista Polaco), de Józef Piłsudski, una formación socialista que defendía el nacionalismo polaco, donde tenían cabida las minorías étnicas. El Polskie Stronnictwo Ludowe (Partido Popular Polaco) de Wincenty Witos, que era representativo de las reivindicaciones del mundo agrario, y $\mathrm{Na}$ rodowa Demokracja (Democracia Nacional), de Roman Dmowski, con una visión de la identidad polaca asentada en su catolicidad y eslavidad.

En aquellos años, los bolcheviques se habían alzado con el poder en Rusia en octubre de 1917 y habían firmado la paz con Alemania. Lenin había ganado la guerra civil a los blancos y luego preparado la expansión internacional de la revolución. La Alemania derrotada, con una enorme población obrera, sin recursos y en la miseria ofrecía una oportunidad única para extender la revolución al corazón de Europa. Entretanto la retirada de los ejércitos alemanes en el este europeo favoreció el nacimiento de nuevas repúblicas. El 14 de febrero de 1920 Lenin tomaba la orden de atacar Polonia, y creaba el frente del oeste. El comandante bolchevique será un brillante antiguo oficial del ejército imperial, Mijaíl Nikoláievich Tujachevski, de ademanes aristocráticos, que contrastaba con uno de sus más famosos subordinados Semión Mijáilovich Budionny, comandante del Primer Ejército de Caballería Roja, situado en Ucrania, quien había cultivado la imagen de horda salvaje para atemorizar al enemigo, arrasando propiedades, violando mujeres y torturando a sacerdotes y oficiales con crueldad.

Józef Piłsudski se preparó con una alianza con el líder nacionalista ucraniano, Simon Petliura, el tratado de Varsovia el 21 de abril de 1920, que confirmaba el apoyo militar polaco a cambio del reconocimiento ucraniano de su frontera occidental. El 25 de abril se inició la ofensiva y el 6 de mayo los polacos entraron en la ciudad de Kiev. Sin embargo, la contraofensiva bolchevique obligo a una retirada total que llevó a los bolcheviques hasta las orillas del Vístula. El 23 de julio Lenin organizo el Comité Revolucionario Polaco, cómo futuro gobierno. Ese mismo día Lenin planteó la idea a Stalin, comisario en el frente sudoeste, de iniciar un avance a Hungría, donde en agosto de 1919 había fenecido la experiencia de la República Popular de Hungría, para entrar en Italia que sufría la formación de comités revolucionarios, que dará nombre al Bienio Rojo. A su vez en Alemania, en enero de 
1919, se había sofocado la revuelta espartaquista, pero la posible llegada de las tropas bolcheviques podría reanudar la revolución, en una Alemania indefensa militarmente. Los bolcheviques necesitaban cruzar Polonia para llegar al corazón de Europa, y la joven república veía enrojecer sus fronteras orientales con el avance revolucionario. En junio la caballería roja de Semión Budionni rompía el frente polaco, y las tropas de Tujachevski, en agosto de 1920 se encontraron en la ribera del Vístula, a la vista de Varsovia.

Polonia se encontraba devastada materialmente, pero no espiritualmente, Jósef Piłsudski organizó el patriotismo y la Iglesia católica levantó la moral. El nuncio papal, el cardenal Achille Ratti, (futuro Pío XI) y un oficial de la misión francesa, Charles de Gaulle, fueron testigos de lo que iba a acontecer. El 15 de agosto, día de la Asunción de la Virgen María, las tropas polacas atacaron el flanco del ejército bolchevique destrozando sus vanguardias. $\mathrm{La}$ arriesgada maniobra envolvente ideada por el mariscal Piłsudski, tendrá finalmente el resultado de destruir parte de las tropas soviéticas de su frente suroccidental, obligando a su retirada ${ }^{1}$. El desastre militar obligó a una paz entre ambos países, firmándose la paz en Riga el 18 de marzo de 1921. Polonia había salvado a Europa momentáneamente de una de sus peores pesadillas. El "Milagro del Vístula" se había producido y el antiguo revolucionario Józef Piłsudski, entraba como héroe en el panteón de los héroes de la historia de Polonia.

El 17 de marzo de 1921 el nuevo Estado polaco se vertebró como una República parlamentaria y el nuevo padre de la Patria abandonó la máxima magistratura en 1922. Sin embargo, en mayo de 1926, protagonizará un golpe de Estado, y aunque no ocupo de nuevo la jefatura del Estado, mantuvo su relevancia política como primer ministro y en la sombra, hasta su fallecimiento de un cáncer el 12 de mayo de 1935. La experiencia de la II República polaca traerá una grata experiencia de pluralidad política, el protagonismo de las vanguardias culturales y la difícil convivencia con unas minorías étnicas que llegaron a representar el $40 \%$ de la población total del nuevo Estado polaco. Las dificultades políticas serán graves, y se materializarán en dos

${ }^{1}$ N. Davies, White Eagle, Red Star: the Polish-Soviet War, 1919-20, Pimlico, London, 2003. A. ZAMOYSKI, Varsovia 1920. El intento fallido de Lenin de conquistar Europa, Siglo XXI, Madrid, 2008. 
magnicidios, el del segundo Presidente de la República, Gabriel Narutowicz, en 1922, y el del ministro del interior, Bronislaw Pieracki, en 1934.

\section{UN JOVEN LLAMADO KAROL}

Es en este periodo convulso y agitado, será cuando nazca nuestro protagonista. Karol Józef Wojtyla, quién nació el 18 de mayo de 1920 en Wadowice, al sur de Polonia. Una localidad de 10.000 habitantes, 2.000 de ellos judíos, con una importante presencia de órdenes regulares: carmelitas descalzos, palotinos y hermanas del Nazareno ${ }^{2}$. El recién nacido era hijo de Karol Wojtyla, un militar del ejército austro-húngaro, integrado en el nuevo ejército polaco y de Emilia Kaczorowska, una profesora de colegio de origen lituano. Su madre falleció poco después a causa de problemas del riñón y del corazón en 1929. Su padre le enseño desde entonces a tener devoción a la Virgen, que sería la madre que velase desde el Cielo por él. Tres años más tarde dejó de existir su hermano mayor Edmund quien, recién graduado de médico, se contagió de una fiebre escarlatina al tratar a sus pacientes. En la escuela secundaria "Marcin Wadowita", el joven Karol destacará como un estudiante con un expediente magnífico, y de buen corazón, al ayudar a comprar su almuerzo aquellos estudiantes que no disponían de suficiente dinero. Con su profesor Kazimierz Forys, descubrirá su vocación de actor y participará en diversas sesiones teatrales. Con el profesor y sacerdote, Edward Zacher, teólogo y astrofísico, ingeniero y un hábil esquiador ${ }^{3}$, profundizará su $\mathrm{Fe}$, convirtiéndose en el presidente de la hermandad mariana de estudiantes de la escuela, durante dos mandatos (1936-38). Sin embargo, cuando el arzobispo de Cracovia, el príncipe Adam Stefan Sapieha visite la escuela, quedará impresionado por las palabras de bienvenida de aquel joven risueño y maduro, preguntó al P. Zacher si aquel joven podría ir al seminario, denegándoselo el profesor, por el fuerte interés que Karol tenía en estudiar Filología Polaca ${ }^{4}$.

\footnotetext{
${ }^{2}$ E. Ferrer, Juan Pablo II. Pregonero de la verdad, Desclee de Brouwer, Bilbao, 2000. P. 31

${ }^{3}$ E. FERRER, op. cit. pp 44-45.

${ }^{4}$ A. Boniecki, The making of the Pope of the Millennium. Kalendarium of the life of Karol Wojtyla, Marian Press, Stockbridge, Massachusetts, 2000, pp. 50-52.
} 
Graduado, cumplió su servicio militar en la $9^{a}$ compañía del $7^{\circ}$ batallón de trabajo de la juventud paramilitar del ejército, en Zubrzyca Gorna, al sur de Wadowice, preparando una carretera entre las montañas.

Después de aquella experiencia se estableció con su padre en Cracovia en 1938. En la histórica ciudad decidiría estudiar filología polaca en la Universidad Jagellónica y también simultanearla con su vocación artística en la escuela de teatro. El aprendizaje de la lengua rusa, la realizará sin problema, y sin mostrar acento. Es su tercera lengua, ya que su padre, como antiguo oficial austriaco, dominaba el alemán y le enseñará el idioma desde pequeño, hablando con él hasta que tuvo un dominio total del idioma germano. En julio asiste al campamento de formación social de la Legión Universitaria en Ozamla, cerca de Sadowa Wizna, para estudiantes.

\section{BAJO LA OCUPACIÓN GERMANA}

El 23 de agosto de 1939, el III Reich alemán y la URSS firmaban el Pacto Ribbentrop-Mólotov. El tratado era un pacto de no agresión, pero añadía un protocolo secreto en el que se detallaba la repartición de los territorios de los Estados soberanos de Estonia, Finlandia, Lituania, Polonia y Rumanía entre ambas potencias.

En 1937, Hitler había exigido la anexión de la ciudad libre de Danzig (Gdansk en polaco), que el Tratado de Versalles había puesto bajo protección de la Sociedad de Naciones, y el acceso ferroviario a través del corredor polaco. Al año siguiente, Alemania aplicó el Anschluss (anexión) de Austria, y poco después de los Sudetes, la región fronteriza, poblada por alemanes étnicos, de Checoslovaquia, siguiéndose con la desmembración de este país. Ante la dejación de Francia y Gran Bretaña, Alemania prosiguió su presión contra Polonia, amparada en su pacto con la URSS.

El 31 de agosto de 1939 un comando de miembros de SD, el servicio secreto del partido nazi, con uniformes polacos, se adueñaron de un puesto aduanero alemán y de la emisora de radio de Gleiwitz, un pueblo fronterizo de la alta Silesia, donde lanzaron proclamas en contra de Alemania y abandonaron los cadáveres de varios nacionalistas polacos asesinados previamen- 
te. Ese mismo día ante el "ataque polaco", el führer dio luz verde a la operación Fall Weiss, que se inició con un ataque aéreo de una hora y la irrupción por la frontera de cincuenta y cuatro divisiones, seis de ellas acorazadas y otras ocho motorizadas, comenzando la Blitzkrieg (guerra rápida). El 17 de septiembre, de acuerdo con el Pacto Ribbentrop-Mólotov, los soviéticos entraron por la frontera oriental adueñándose de las provincias del este y de las tropas polacas situadas allí. El 6 de octubre la campaña de Polonia había finalizado, el balance fue de 70.000 polacos muertos y 134.000 heridos; y 16.000 soldados germanos muertos y 32.000 heridos.

Sin embargo, grupos especiales germanos habían iniciado la ejecución masiva de judíos y nacionalistas polacos para desarticular una posible resistencia. En su parte, los soviéticos eliminaron a las élites polacas, el caso más clamoroso fue la matanza de Katyn, donde fueron asesinados 22.000 oficiales de las tropas rendidas por los soviéticos, para crear una nueva sociedad comunista, eliminando sus elementos contrarrevolucionarios. A su vez, en la parte ocupada por los germanos, se eliminó a la élite polaca (profesores, sacerdotes, profesiones liberales...) para reducir a su población a una masa amorfa de trabajadores esclavos, bajo el control de capataces alemanes étnicos y colonizadores alemanes.

En Cracovia, la universidad fue cerrada por los ocupantes alemanes y los profesores fueron detenidos y deportados a un campo de concentración. El joven universitario sobrevivió trabajando en la cantera de Zakrzowek y después en la fábrica química "Solvay". El trabajo duro le puso en contacto con el mundo del trabajo manual, que nunca olvidará, y le ayudó a evitar su deportación a las fábricas de Alemania. En 1941 falleció su padre, quedando sólo en el mundo y sintiendo una soledad que no se llena. Al mismo tiempo, participó en la resistencia cultural del grupo Unia, donde fundó el Teatro Rapsódico, junto a Mieczyslaw Kotlarczyk. Ambos reunieron un equipo que ensayaban y actuaban en casas particulares obras de índole patriótica, de forma clandestina. Kotlarczyk era de Wadowice y había estudiado Filología Polaca en la Universidad Jagellonica también, aunque era doce años mayor que $\mathrm{Karol}^{5}$. Las actividades estaban

${ }^{5}$ C. KutA, "Mieczysław Kotlarczyk. A Teacher and Artistic Friend of John Paul II" en The Person and the Challenges. The Journal of Theology, Education, Canon Law and Social Studies Inspired by Pope John Paul II, Volume 9, № 1, 2019, pp. 111-126. 
prohibidas por las fuerzas de ocupación bajo pena de deportación incluso de muerte.

A nivel espiritual, su vida se vio transformada por un humilde sastre, Jan Tyranowski, quién había trabajado con la Acción Católica. Durante la ocupación, los 9 padres salesianos de la parroquia de "San Estanislao de Kostka" de Cracovia fueron deportados a campos de concentración en 1940, falleciendo allí. Jan Tyranowski se hizo cargo del apostolado juvenil masculino, llevando los grupos de Rosario viviente, donde conocería a Karol Wojtyla, a quien descubriría la mística carmelitana española de santa Teresa de Jesús y de san Juan de la Cruz. De aquellos círculos de formación, de una docena de personas, surgieron unas once vocaciones sacerdotales, uno de ellos será Karol. El joven huérfano siempre verá en el sastre Jan, quién supo encauzar su vocación ${ }^{6}$. Karol decidió hablar con el P. Józef Prus, carmelita de Wadowice, quién por la situación de ocupación, le aconsejó que volviese al final de la guerra ${ }^{7}$.

Karol se despide de los ensayos teatrales de su amigo Kotlarczyk, a quien admira y ha recogido en su casa junto a su familia al quedarse sólo, tras el fallecimiento de su padre el 18 de febrero de 1941. Será entonces cuando hable con el cardenal príncipe Adam Sapieha, quién lo admitirá como aspirante en su seminario clandestino. En ese momento Karol simultánea su trabajo en Solvay con sus estudios secretos. En marzo de 1943 interpretará el papel de protagonista en la obra "Samuel Zborowski" de Juliusz Słowacki. Es su última representación en las escenas teatrales clandestinas. Sin embargo, la represión era continua por parte de la Gestapo, uno de sus compañeros, Jerzy Zachuta, quién lo acompañaba al arzobispado a diario, no apareció. Su nombre aparecerá entre los rehenes fusilados unos días más tarde ${ }^{8}$. A pesar de todo, el 29 de febrero de 1944 un camión militar lo atropella gravemente, un oficial alemán y una mujer lo salvan llevándolo a un hospital. Ante el peligro de las deportaciones, el arzobispo-cardenal pide a los seminaristas que se refugien en el Palacio arzobispal. No obstante, Karol corre un

${ }^{6}$ J. Kwitny, L'uomo del secolo, Piemme, Casale Monferrato, 2002, pp. 48-49.

${ }^{7}$ T. Szulc, Joao Paulo II. A vida de Karol Wojtyla, Editorial Noticias, Lisboa, 1995, p. 129.

${ }^{8}$ L. AcAtToli, Karol Wojtyla: el hombre más famoso del siglo XX, San Pablo, Bogota, 2006, p. 24. 
gran peligro, ya que su nombre figura como obrero en la fábrica Solvay, y ante su incomparecencia al trabajo, la policía se pone a buscarlo. Un amigo suyo conseguirá hacer desaparecer su nombre de la lista de personal.

El final de la guerra llegará pronto, los alemanes huyen y son sustituidos por los soviéticos quienes liberan el país, pero exclusivamente para instaurar otro régimen totalitario. Karol Wojtyla será elegido vicepresidente de la organización estudiantil "Bratnia Pomoc" de la Universidad Jagellónica, que se dedicaba a socorrer a los estudiantes desamparados después de la guerra, especialmente en asunto de vivienda.

\section{LA OTRA OCUPACIÓN}

El sacrificio polaco no servirá para preservar la soberanía de su nación. 6 millones de polacos habían muerto durante el conflicto, la mitad por su condición judía. En cuanto a la Iglesia, pagó su tributo en sangre, con la vida de 4 obispos, 2.647 sacerdotes, 113 seminaristas y 238 religiosas asesinados por los alemanes. Las reivindicaciones territoriales soviéticas serán aceptadas por sus aliados occidentales, a espaldas del legítimo gobierno polaco. La aceptación del cambio de fronteras, con su obligado traslado poblacional de millones de personas, fue el mayor realizado en la historia del continente. Sus antiguas provincias orientales, de población mixta, fueron «limpiadas» de sus elementos polacos, primero por los nacionalistas ucranianos y luego finalizada por los soviéticos. La nueva Polonia comunista se erigirá sobre un nuevo territorio, más pequeño, pero con una población homogénea en sus referencias lingüísticas, culturales y religiosas ${ }^{9}$. La construcción de los nuevos poderes comunistas con Bolesław Bierut, supuso el mantenimiento del gobierno en el exilio de Londres, reconocido exclusivamente por el Vaticano, Irlanda y España, a nivel internacional y seguido por una diáspora amplia de veteranos del ejército del general Władysław Anders.

Entretanto, en la República Popular de Polonia, la Iglesia católica se convertía en la única institución que podía salvaguardar la identidad del pueblo

\footnotetext{
${ }^{9}$ K. Lowe: Continente salvaje, Galaxia Gutenberg, Barcelona, 2015, pp. 253-293.
} 
polaco, como en los tiempos del siglo XIX. En 1948 había muerto el primado, cardenal Hlond, y fue designado arzobispo de Varsovia y Gniezno, tradicional sede de los primados de Polonia, Stefan Wyszynski, obispo de Lublin, y que era el más joven del episcopado polaco. En 1950 como primado de la iglesia católica de una Polonia subordinada a la URSS, tuvo que aceptar el acuerdo propuesto por el gobierno comunista. En 1953 el Papa Pío XII le nombró cardenal, pero no pudo ir a Roma a tomar posesión del cargo. En el mismo año publicó su famosa carta pastoral "Non Possumus", en la que se oponía a la intervención gubernamental en los nombramientos eclesiásticos y en el intento de dominio comunista de la Iglesia en Polonia. Por esta razón fue arrestado por la policía y aislado tres años en prisión. La persecución llevó a la detención de 900 sacerdotes y algunos obispos, y dos años después la de otros dos millares de sacerdotes y seglares comprometidos en la defensa de la Iglesia.

\section{EL JOVEN SACERDOTE KAROL}

Karol continuó sus estudios en el Seminario Mayor de Cracovia y en la Facultad de Teología de la Universidad Jagellónica, hasta su ordenación sacerdotal el 1 de noviembre de 1946 de manos del Arzobispo príncipe Sapieha. El joven de Wadowice había pedido al arzobispo su dispensa para irse al Carmelo de Czerna, donde su prior, el P. Alfonso María Mazurek, había sido fusilado por los alemanes, y a quien Karol conoció en Wadowice. Sin embargo, el arzobispo no se dejó arrebatar aquella joya que aún permanecía en su seminario ${ }^{10}$. El gobierno comunista le autorizó dos pasaportes para poder enviar a estudiar al exterior a dos sacerdotes. Uno de ellos sería Karol Wojtyla, el otro Stanislaw Starowieyski.

A pesar del prestigio de la universidad Gregoriana, regida por los jesuitas, el arzobispo prefirió que estudiase en el Angelicum de los dominicos, donde el neotomismo tenía su baluarte principal ${ }^{11}$. Karol estudiará en Roma

\footnotetext{
${ }^{10}$ B. LeComte, Joao Paulo II. A tao esperada biografia do último "gigante" da nova época, Ambar, Porto, 2005, p. 108.

${ }^{11}$ J. Kwitny, L'uomo del secolo, Piemme, Casale Monferrato, 2002, p. 72.
} 
de 1946 a 1948, aunque tendrá oportunidad de visitar Francia y Bélgica, donde conocerá la experiencia de los curas obreros. En Roma su residencia será el Colegio belga, donde aprenderá francés e inglés. El padre GarrigouLagrange O.P., quién era su profesor de teología dogmática y espiritual, se convirtió en director de la tesis doctoral de Karol Wojtyla. Se doctoró en Teología con la tesis "El acto de fe en la doctrina de san Juan de la Cruz". En sus conclusiones relata como para conocer a dios se necesitaba más que la razón, era un encuentro personal con Dios, y esa comunión mística se hacía con la plena libertad del que disfrutaba la experiencia del encuentro con Dios $^{12}$. Al no poder imprimir su tesis, terminará de doctorarse en la Jagellónica.

A su vuelta a Polonia, es nombrado vicario de la parroquia de Niegowic, en Wieliczka, donde está de párroco Kazimierz Buzala, con el que aprenderá la dura vida de pastorear a una comunidad sencilla, laboriosa y pobre. Su año de estancia le servirá para organziar el Rosario viviente y alguna celebración teatral para los más chicos e la parroquia. Poco después será nombrado vicario en San Florían, en Cracovia, donde hay una fuerte presencia de estudiantes, con los que inicia su apostolado juvenil. Tampoco abandonó su vocación de poeta, publicando en la revista Tygodnik Powsszechny, su poema "Piesn o blasku wody", con el pseudónimo de Andrzej Jawien ${ }^{13}$. El 23 de julio de 1951, el cardenal príncipe, Adam Sapieha, fallecía en el palacio arzobispal, siendo sustituido en sus funciones por Eugeniusz Baziak, como Administrador Apostólico de Cracovia. Baziak era el Arzobispo de Lwow, de donde había sido expulsado por las autoridades soviéticas, al quedar aquella región incorporada a la URSS. No obstante, el 16 de diciembre de 1952, fue arrestado bajo sospecha de espionaje. La causa real era haberse negado a condenar a 6 sacerdotes arrestados por cargos de espionaje a favor de los EEUU. Después de 8 días de interrogatorios, fue puesto en libertad con la orden de abandonar Cracovia. Se quedó en Tarnów, en la casa de su madre y su hermana. De donde pudo regresar a Cracovia en 1956, con el nuevo gobierno

${ }^{12}$ G. Weigel, Biografía de Juan Pablo II. Testigo de la esperanza, Plaza y Janés, Barcelona, 1999, pp. 127-129.

${ }^{13}$ A. BONIECKI, The making of the Pope of the Millennium. Kalendarium of the life of Karol Wojtyla, Marian Press, Stockbridge, Massachusetts, 2000, pp. 118-125. 
comunista de Gomulka. El 25 de septiembre de 1953 lo era a su vez, el primado de Polonia, cardenal Wyszyński quién será confinado inicialmente en Rywałd, no saldrá de su cautiverio hasta 1956 también. La Iglesia era descabezada, después de haber firmado un acuerdo con el gobierno comunista, pero estos querían su colaboración o extinción.

La lucha iba a ser cultural, lo intuyó el príncipe Sapieha, quién quería que Wojtyla se preparase como intelectual. Baziak siguió aquellas recomendaciones y cuidó de forma partenal al joven sacerdote. Karol tomó cariño al arzobispo errante y siguió sus estudios en la Jagellónica donde realizará su tesis de habilitación en filosofía sobre Max Scheler: "Valoración sobre la posibilidad de construir la ética cristiana sobre las bases del sistema de Max Scheler". La fenomenología realista de Scheler podía combinarse con el neotomismo y renovar las bases de la ética a través de su recurso sobre la moral. Cómo miembro externo de su tribunal participará el historiador de Filosofía Stefan Swiezawski, de KUL (Universidad Católica de Lublin). La tesis de Karol fue la última que se defendió en la facultad de teología antes de ser disuelta por el gobierno. Cómo no podía dar clase en la Jagellónica, fue nombrado profesor de Teología moral y Ética social del seminario metropolitano de Cracovia en 1953.

Sin embargo, el profesor Swiezawski le propuso impartir clases de Ética en la Facultad de Filosofía de la Universidad Católica de Lublin, en la que dos años después fue nombrado director de dicha cátedra. En la universidad católica de Lublin impartió sus cursos hasta 1961, simultaneándolo con sus labores sacerdotes en Cracovia ${ }^{14}$. Los 340 kilómetros que separan Cracovia de Lublin eran superados con 8 horas de lectura en el tren. En KUL, Karol Wojtyła reunió en torno suyo a un grupo de profesores que conformaran la Escuela Ética de Lublin: Stanislaw Grygiel, Jozef Tischner, Marian Jaworski y Tadeus Styczen. KUL fue una excepción, a pesar de las restricciones, fue el único centro educativo superior católico en el mundo comunista ${ }^{15}$.

Sin embargo, su vida iba a cambiar. El arzobispo Eugeniusz Baziak soli-

${ }^{14}$ G. Weigel, Biografía de Juan Pablo II. Testigo de esperanza, Plaza \& Janés, Barcelona, 1999, p. 175.

${ }^{15}$ B. LeComte, Joao Paulo II. A tao esperada biografia do último "gigante" da nova época, Ambar, Porto, 2005, pp. 146-147. 
citó al primado la necesidad de tener un obispo auxiliar, y no quería que fuese un premio para un sacerdote veterano, sino un colaborador joven y activo que le complementase en el trabajo. El elegido fue Karol, quién sólo tenía 38 años, y fue llamado por el primado a Varsovia, presentándose con su sencilla sotana y sus zapatos agujerados. El joven sacerdote estaba acompañando a sus estudiantes en una excursión para practicar canoa cerca de Olsztyn. En aquel tiempo, Karol, a quien llamaban sus estudiantes wujek, tío para esconder su condición sacerdotal ante los oídos indiscretos de los chivatos de la policía comunista, pasaba una parte de sus vacaciones en las montañas de Bieszczady o en los lagos Masurianos junto a sus chicos.

En 1958 fue nombrado Obispo Titular de Olmi y Auxiliar de Cracovia por Pío XII y en septiembre recibió la ordenación episcopal de manos del Arzobispo Eugeniusz Baziak. Para Karol fue un momento emocionante, porque la ordenación episcopal tiene su herencia directa en los apóstoles y, en el caso de Baziak, lo ponía en relación con la diócesis de Lwow, un lugar muy particular donde históricamente habían residido tres obispos católicos: de rito romano, griego y armenio respectivamente. Con el gobierno soviético se suprimieron en beneficio de la Iglesia ortodoxa. Aquel hecho histórico era muy valorado por el nuevo obispo auxiliar, porque le ponía en contacto directo con el cristianismo oriental, el otro pulmón de la Cristiandad, a través de la consagración de aquel arzobispo que había sufrido tanto en su carnes ${ }^{16}$. Desde entonces acompañará los últimos cuatro años de vida del administrador apostólico de Cracovia. En ese interregno, Karol demostrará no ser sólo un sacerdote intelectual que sabe moverse entre profesores y estudiantes, sino que es capaz de comprender la situación real de obreros y campesinos, como demuestran sus pastorales.

\section{UN OBISPO FUERA DE LO COMÚN}

En 1956 la desestalinización trajo un cambio profundo en Polonia. Sin embargo, en Poznan, los obreros polacos de la factoría Cegielski aprovecharon

\footnotetext{
${ }^{16}$ JuAn PaBlo II, ;Levantaos, vamos!, Plaza \& Janés, Barcelona, 2004, pp. 20-38.
} 
para convocar una huelga contra "la burguesía roja". La represión causó centenares de muertos, aunque las consecuencias favoreciendo la asunción del poder del ala más nacionalista de los comunistas. El VII pleno del Comité Central del PZPR nombró como primer secretario a Władysław Gomułka, quién inicio "el camino polaco hacia el socialismo" paralizó la colectivización del campo, autorizó la construcción de nuevos templos y permitió la liberación del primado del cardenal Wyszynski. La apertura favoreció la aparición de algunas revistas católicas, donde se ira formando un sustrato de intelectualidad católica consentida, el futuro Club de los Intelectuales Católicos (Klub Inteligencji Katolickiej). En 1957 se abrirán cinco clubes KIK, dos en Cracovia. El KIK de Varsovia creó la revista "El vínculo" ("Wiez"), que dirigirá el periodista Tadeusz Mazowiecki ${ }^{17}$.

La diferencia contrastaba con Hungría, donde la rebelión anticomunista triunfó momentáneamente, hasta ser aplastada por las fuerzas soviéticas, sin recibir ayuda de occidente, con la excepción del gobierno español ${ }^{18}$. El cardenal Mindszenty, quién mantuvo una posición de choque con el gobierno comunista, había sido detenido, torturado y encarcelado en 1948, pudiendo ser liberado durante la revuelta, para refugiarse en la embajada estadounidense donde estuvo enclaustrado hasta 1971, cuando pudo trasladarse al exilio, falleciendo cuatro años después.

El cardenal Wyszynski, desde 1956 hasta 1966, realizó un gran programa evangelizador, a causa de la Gran Novena iniciada por el Milenario del Bautismo de Polonia. El aniversario debía servir para la renovación moral de la patria y el ofrecimiento de los polacos a la protección de la Virgen Maria, Reina de Polonia, la imagen de Częstochowa. Juan II Casimiro había consagrado todo el país bajo la protección de la Virgen de Jasna Góra, hace trescientos años, a consecuencia del asedio sueco que sufrió en los tiempos del denominado "El Diluvio", no siendo conquistada, y reiniciándose la reconquista del país. La imagen de Częstochowa, se convirtió desde entonces en el santuario mariano con un mayor significado patriótico. En tiempos difíciles,

${ }^{17}$ B. LeComte, Joao Paulo II. A tao esperada biografia do último "gigante" da nova época, Ambar, Porto, 2005, p. 195.

18 A. ANDERLE, "La intervención española en la revolución húngara de 1956", en HAOL (Historia Actual Online) n n 10, Primavera, 2006, pp. 115-123. 
los polacos peregrinaban a miles a orar ante el icono de la Virgen negra. Durante la Segunda Guerra Mundial, ante la imposibilidad de hacerlo, se mantuvo la tradición, enviando una delegación de estudiantes, entre los cuales participó Karol Wojtyla ${ }^{19}$.

La imagen santa de Częstochowa fue paseada por todo el país, y las representaciones de su icono fueron entronizadas en las 11.000 parroquias. Miles de peregrinos asistieron a la renovación de la Consagración de Polonia a la Virgen, oyendo los juramentos de Jasna Gora, que el primado había escrito para la ocasión: "Te juramos educar a la joven generación en la fidelidad a Cristo, defenderla del ateísmo y la descomposición, y envolverla en un atento cuidado paternal" ${ }^{20}$. Cuando finalizó la Gran Novena, Karol Wojtyla había oficiado 53 Misas, cuyas homilías estuvieron dedicadas a la historia de Polonia ${ }^{21}$. Aquel movimiento de renovación espiritual movió los corazones, fortaleció la Fe de los polacos, y nutrió la catolicidad de la identidad patriótica polaca.

Sin embargo, aquel joven obispo auxiliar tampoco dejó el pulso del mundo académico, donde seguía dando clase en KUL. En 1960 publicó “Amor y responsabilidad", una de sus principales obras, hijas de la comunicación con sus alumnos y los problemas que les importaba. En ella Karol Wojtyla establecía un nuevo paradigma para entender la sexualidad, integrándola en el marco de las relaciones interpersonales del hombre y de la mujer, regidas por la norma personalista. Las relaciones sexuales eran queridas por Dios, pero dentro de una entrega total, que se daba en el matrimonio, un verdadero amor, y no la búsqueda del placer usando al otro. Le ayudaron a preparar su obra su amigo filósofo Andrzej Półtawski y du mujer Wanda Półtawska, médico psiquiatra, quién en su época de scout, participó en la resistencia, siendo condenada al campo de concentración femenino de Ravensbrück donde sirvió de cobaya en los experimentos del Dr. Karl Gebhardt. Ella tuvo una gran amistad con Karol, desde una década antes, cuando era vicario en

\footnotetext{
${ }^{19}$ JuAn Pablo II, ;Levantaos, vamos!, Plaza \& Janés, Barcelona, 2004, pp. 54-60.

${ }^{20}$ A. Ramos y B. Avalos: Juan Pablo II. Peregrino de la Esperanza, Reader's Digest, México, 2004, p. 99.

${ }^{21}$ B. LeComte, Joao Paulo II. A tao esperada biografia do último "gigante" da nova época, Ambar, Porto, 2005, pp. 201-204.
} 
San Florían, donde ella acudió en busca de un director espiritual que le curase su alma rota en el campo de concentración. En 1967, será ella quién por consejo de Karol, organice el Instituto de Teología Familiar en la Facultad Pontificia de Teología de Cracovia, que gestionaría durante 33 años ${ }^{22}$.

En junio de 1962 fallecía monseñor Baziak y en enero de 1964, Karol Wojtyła fue nombrado Arzobispo de Cracovia por Pablo VI, después de haber ejercido como vicario capitular. En su diócesis se hace presente ante sus feligreses, especialmente llevando el perdón a los enfermos, hablando con ellos y con sus allegados presentes. Es un arzobispo que toma el pulso de la realidad hablando con sus feligreses de toda condición. Su fama es de una persona dialogante, consigue mantener el edificio del seminario, aunque cediendo una planta, ante la orden de expropiación del edificio. Se preocupa por elevar la formación de sus sacerdotes en el seminario, ante la ausencia de una facultad de Teología en la universidad. También consigue la mejor red catequética de Polonia, al ceñirse a la ley, y pedir permiso a las autoridades, después de pagar las multas de los párrocos acusados de dar enseñanza sin permiso.

Sin embargo, también demostrará su tenacidad. En la nueva ciudad de Nowa Huta, donde se habían construido los mayores Altos Hornos del país, con capacidad para 40.000 trabajadores, que residirían con sus familias en una nueva ciudad sin iglesias, modelo de una sociedad socialista, cuna del nuevo polaco comunista. En el barrio de Bienczyce, las autoridades comunistas habían concedido el permiso para construir una iglesia. No obstante, las autoridades decidieron revocarlo para convertirla en una ciudad modélica de la nueva Polonia. La gente se opuso inmediatamente y los enfrentamientos con la policía, produjeron víctimas. Los obreros levantaron una Cruz en el lugar donde querían hubiese una iglesia, y la policía la derribaba, para ver como por la noche se había erigido una nueva. El obispo auxiliar Wojtyla junto a otros sacerdotes celebraron la misa a cielo abierto, el tiempo que duro el conflicto, desde 1960 hasta 1967. El ya arzobispo Wojtyla se mantuvo tenaz al lado de la comunidad, y el 14 de octubre de 1967 celebró la Misa con la que se ponía la primera piedra de la Iglesia. Cada vecino fue aportan-

${ }^{22}$ W. PoŁtawsKa, Diario de una Amistad, San Pablo, Madrid, 2008, pp. 14-16. 
do una piedra para hacerla suya, y que finalmente fuese fruto del esfuerzo conjunto de todos. Sin embargo, en otros sitios, como en Mistrzejowicw, el resultado fue diferente, su párroco, D. Jerzy Kurzeja murió tras el interrogatorio realizado por la policía ${ }^{23}$.

\section{LA RENOVACIÓN DEL CONCILIO VATICANO II}

Entre el 31 de enero y el 6 de abril de 1965 participó de forma activa como experto en el Concilio Vaticano II. En aquel momento Karol Wojtyla, a sus 42 años, era uno de los obispos más jóvenes del Concilio. Su aportación fue muy importante en la redacción de la Gaudium et spes, la Constitución Pastoral sobre la Iglesia en el mundo actual, y del texto final de la Declaración conciliar Dignitatis humanae, que reunía los principios básicos de una teología positiva de la libertad religiosa, muy diferente a la planteada por el liberalismo, que consistía en la desaparición del sentimiento religioso de la vida pública. En ella se afirmaba la dignidad del ser humano en cuanto sujeto, creado a imagen y semejanza de Dios, y que alcanzaba su plenitud actuando en libertad, buscando la verdad, y en ese goce de la libertad entraba en la adhesión libre, personal y consciente de amar a Dios, dándose sentido a una vida en el mundo. La libertad religiosa tenía su origen en la propia revelación.

A partir de este concepto de libertad, el diálogo ecuménico se hacía posible, no cómo una mera tolerancia que podía favorecer las diferencias, sino hacia la aceptación total, de todas las partes, de la verdad. Porque únicamente el descubrimiento de la verdad ayudaría al cristianismo a superar sus múltiples separaciones, como el futuro cardenal Newman había descubierto, desde su inicio como pastor anglicano. Poco después de terminado el Vaticano II, el Arzobispo Wojtyla publicó en 1972, un libro con su experiencia sobre el Concilios $^{24}$. Su papel sería reconocido por Pablo VI, que había sido elegido Papa en 1963, en pleno Concilio, tras el fallecimiento de Juan XXIII.

\footnotetext{
${ }^{23}$ JuAn PABLo II, ;Levantaos, vamos!, Plaza \& Janés, Barcelona, 2004, pp. 77-81.

${ }^{24}$ JuAn PABLo II, La renovación en sus fuentes. Sobre la aplicación del Concilio Vaticano II, BAC, Madrid, 1982.
} 
Pablo VI había sido como cardenal Montini, Arzobispo de Milan, y había ocupado la Secretaría de Estado anteriormente con Pío XII. En el consistorio del 26 de junio de 1967 Pablo VI nombraba cardenal al Arzobispo de Cracovia. En ese mismo acto fue creado cardenal, el arzobispo de Filadelfia John Joseph Krol, en realidad Jan Józef Krol, hijo de exiliados polacos en EEUU. Existía la costumbre, que con la elección de un cardenal, el nuevo príncipe de la Iglesia entraba con su birrete en su localidad de origen. Al arzobispo de Filadelfia le fue negada la visita a la localidad de sus padres en Siekierczyna. Sin embargo, la tradición se salvó al ser Karol Wojtyła quién compareció en lugar de su amigo ${ }^{25}$. El cardenal Krol también había participado como asesor en el Concilio Vaticano II, compartiendo parecidas ideas a su compañero de Wadowice.

La presencia de dos cardenales polacos, no supondrá ningún problema para el liderazgo de la Iglesia católica en Polonia. Para el más joven, siempre dejó al primado Wyszynski la preeminencia, sintiendo una gran admiración por quién había vivido; la Polonia repartida, la independencia, la ocupación y lideraba la lucha por la libertad de conciencia y religiosa del pueblo polaco. La Gran Novena fue su modo de estrechar la relación entre Iglesia y pueblo ${ }^{26}$.

En este periodo será también cuando protagonice su primer viaje a la América sajona. El primer viaje será a Canadá y a los Estados Unidos desde el 28 de agosto hasta el 10 de septiembre de 1969. El Congreso de la comunidad Polaco-canadiense y el Seminario Polaco de Orchard Lake invitaron al cardenal Wyszynski, pero declinó a favor de Wojtyła. El cardenal Wojtyła fue acompañado de Szczepan Wesoly, Stanislaw Dziwisz y Franciszek Macharski. Visitaron a las comunidades polacas de Canadá y de Estados Unidos y tuvieron su primera experiencia con la democracia, el relativismo, el consumismo y el nivel de vida de los polacoamericanos ${ }^{27}$. En este viaje su inglés se fue perfeccionando sobre la marcha y pudo visitar a los cardenales ameri-

\footnotetext{
${ }^{25}$ A. Ramos y B. Avalos, Juan Pablo II. Peregrino de la Esperanza, Reader's Digest, México, 2004, p. 100.

${ }^{26}$ A. Ricardi, Juan Pablo II. La Biografia, San Pablo, Madrid, 2011, pp. 147-150.

${ }^{27}$ A. Ramos y B. Avalos, Juan Pablo II. Peregrino de la Esperanza, Reader's Digest, México, 2004, p. 95.
} 
canos y conocer unos puntos de vista nacidos de una sociedad muy diferente a la polaca ${ }^{28}$.

El 5 de octubre de 1973 tuvo la Visita "ad Limina" ante el Papa Pablo VI. En abril del año siguiente participó en el Congreso con motivo del VII centenario de Santo Tomás que se celebró en Italia.

En 1973 su viaje fue al otro lado del mundo. El congreso eucarístico de Melbourne le dio la oportunidad de conocer Australia, Nueva Zelanda y Papúa Guinea. Ese mismo año el cardenal tuvo la visita de Ana Teresa Tymieniecka, una polaca de Masovia que había abandonado Polonia en 1946. En el exilio había estudiado filosofía en París, doctorándose en Friburgo y colocándose como profesora en Estados Unidos. La profesora Tymieniecka había publicado un libro "Eros y Logos" en clave fenomenológica, por lo que cuando descubrió en 1972 la edición polaca de "Persona y Acción" (Osoba i Czyn), que había publicado Wojtyla en 1967. Le sorprendió las afinidades con aquel desconocido sacerdote que compartía un parecido punto de vista. La profesora Tymieniecka le ofreció publicar una en versión en inglés de su obra, firmada por los dos. La versión definitiva, ampliada por Tymieniecka, se publicará en inglés en 1979, y se titulará "The Acting Person", sin el permiso del Vaticano, que guardará celosamente los derechos de autor del recién elegido Papa Juan Pablo II.

La profesora Tymieniecka estaba bien relacionada con el mundo académico y la alta sociedad estadounidense, por su matrimonio con el profesor Hendrik Houthakker, profesor de la universidad de Harvard y asesor económico de Richard Nixon. Entre 23 de julio y 5 de septiembre de 1976 el cardenal Wojtyła realizó un viaje pastoral y académico a Estados Unidos y Canadá. El matrimonio Houthakker le consiguió una cena en casa del presidente de Harvard (de 250 personas) donde fue presentado como "el futuro papa". Ya Bernard Guetta había calificado en el Nouvel Observateur a Wojtyla como "el Papa de los disidentes". En aquel viaje conocerá al profesor Zbigniew Brzezinski, de origen polaco, que después sería consejero de seguridad del presidente Carter. El cardenal Wojtyła tenía una visión crítica sobre la moral social estadounidense, pero el ma-

${ }^{28}$ T. SzUlC, Joao Paulo II. A vida de Karol Wojtyla, Editorial Noticias, Lisboa, 1995, p. 258. 
trimonio Houthakker intentará convencerle de las ventajas de la democracia norteamericana ${ }^{29}$.

En este viaje el cardenal Wojtyła participó en el Congreso Eucarístico de Filadelfia y dio una conferencia sobre "La trascendencia de la persona en el acto humano y en la autodefinición del hombre" en la Universidad Católica de Washington ${ }^{30}$. Las actuaciones del cardenal Wojtyla serían vigiladas por el Servicio de Seguridad del Ministerio de Asuntos Interiores (Służba Bezpieczeństwa), que grabaron sus conversaciones para encontrar algún punto débil para poder chantajearle como hicieron con otros, pero sin encontrar ningún aspecto por el que pudieran amenazar su independencia. El SB se infiltró en el clero polaco para controlar a la oposición política, se calcula que un millar de clérigos tuvo algún tipo de colaboración con el servicio de seguridad comunista ${ }^{31}$. El P. Konrad Hejmo O.P., que llegará a ser subdirector de la Oficina de Prensa del Episcopado polaco en Roma, será uno de los colaboradores más importantes del SB, en los años setenta y ochenta.

Sin embargo, aquellos viajes no reducían su labor como Arzobispo de Cracovia. Karol Wojtyła quería llevar los frutos del Concilio Vaticano II a su diócesis, y el mismo concilio había resaltado la importancia del sínodo diocesano, como asamblea que ayudase al obispo, formada por sacerdotes y laicos relevantes. El Sínodo diocesano resaltaba la necesidad de vivir la pertenencia a la Iglesia a partir de la comunión entre todos los bautizados. Actualmente el canon 460 describe el sínodo diocesano como «reunión ("coetus") de sacerdotes y de otros fieles escogidos de una Iglesia particular, que prestan su ayuda al Obispo de la diócesis para bien de toda la comunidad diocesana ${ }^{32}$.

El 8 de enero de 1972 se iniciará la apertura del Sínodo de la Arquidiócesis de Cracovia, que será convocado solemnemente el 1 mayo de 1972. El

\footnotetext{
${ }^{29}$ C. Bernstein y M. Politi, His holiness. John Paul II and the hidden history of our time, Doubleday, New York, 1996, pp. 136-147.

${ }^{30}$ T. SzUlc, Joao Paulo II. A vida de Karol Wojtyla, Editorial Noticias, Lisboa, 1995, pp. 258-259.

${ }^{31}$ D. YALLOP, The power and the glory, Carroll \&Graf Publishers, New York, 2007, p 10.

${ }^{32}$ Constitución Apostólica Sacrae disciplinae leges, del 25 de enero de 1983 (AAS 75 [1983], vol. II, pp. VII-XIV).
} 
programa de trabajo preveía un período de trabajo que iba desde el 8 de mayo de 1972 al 8 de mayo de 1979. Cómo era costumbre en él, el Sínodo debía servir también de conmemoración del noveno aniversario del martirio del obispo San Estanislao (1072-79). Este trabajo se realizó a través de la actividad de centenares de grupos de estudio de estudios sinodales, formados en su mayor parte por católicos laicos. En 1977 los grupos llegaban al número de 503, reuniendo a 9.000 personas, de los cuales 4.000 eran jóvenes, estudiantes y trabajadores ${ }^{33}$. Los componentes debían ser personas capacitadas que aportasen un enriquecimiento al sínodo. Los directores de los grupos mantenían un contacto regular con ellos, y ellos a su vez eran ratificados por la Comisión Central. Este comportamiento era para evitar la posible de entrada de miembros del grupo $\mathrm{PAX}^{34}$, o de personas enemigas de la Iglesia, que hubiesen aprovechado el momento para sabotear desde dentro el trabajo del Sínodo ${ }^{35}$.

La participación en el sínodo será numerosa y sabrá proporcionar ese sentido comunitario a la sociedad polaca, desvertebrada por los comunistas para ejercer un mejor control sobre ella. Para el arzobispo el sínodo tiene un papel determinante en el proceso de revitalizar la reevangelización de la sociedad polaca, al completar la misión de la Gran Novena del Milenario, con un sínodo, a nivel exclusivo de la diócesis de Cracovia, donde se ponía en contacto a los expertos con equipos surgidos de la comunidad católica. Las enseñanzas de que la Iglesia era una comunidad formada por todos los católicos, debía ser analizada bajo la luz del Concilio Vaticano II. El cardenal Wojtyła era uno de los más preparados por ser miembro del consejo del Sínodo de los Obispos, como dejaría constancia del 27 de septiembre al 26 de octubre de 1974 en la III Asamblea General Ordinaria del Sínodo de los Obispos, cómo orador de la parte doctrinal. Este organismo, el Sínodo de los obispos tendrá cinco sesiones hasta 1978.

\footnotetext{
${ }^{33}$ K. Wojtyla, Sínodo diocesano dell'arcidiocesi di Cracovia. 1972-1979, Librería Editrice Vaticana, Città del Vaticano, 1985. p. 143.

${ }^{34}$ El movimiento Pax fue fundado por Bolesław Piasecki, orientado por el KGB, sirvió para infiltrar a la Iglesia Católica y establecer lazos con movimientos cristianos de izquierda en el oeste europeo.

${ }^{35}$ K. WOJTYLA, op. cit. 1985, p. 49.
} 
El arzobispo de Cracovia es una persona querida por el Papa Pablo VI. Entre 1973 y 1976 será citado once veces ante su Santidad, y en 1976 le será encargada la predicación de los ejercicios espirituales ante la curia ${ }^{36}$. Sin embargo, Pablo VI había iniciado la Ostpolitik, un diálogo con las autoridades comunistas que llevase a la supervivencia de la Iglesia en el este, desde una posición de debilidad, haciendo caso del consejo de personas de confianza de occidente. Una de aquellas medidas de confianza, sería la destitución del cardenal Mindszenty, símbolo de la resistencia magiar, por el papa Pablo VI, sin que ello significase ningún cambio favorable para los católicos de Hungría. En Polonia no se excluía la posibilidad de una destitución parecida del cardenal y primado Stefan Wyszynski. En junio de 1973, monseñor Agostino Casaroli, que será en 1979 pro-Secretario de Estado, hablaba con el ministro polaco de Asuntos Exteriores, Olszowski, con motivo de la Conferencia de Seguridad europea en Helsinki. En noviembre del mismo año, Olszowski visitará el Vaticano, obteniendo una audiencia con Pablo VI ${ }^{37}$. En febrero de 1974, monseñor Agostino Casaroli visitará Polonia, como secretario del Consejo para los Asuntos Públicos de la Iglesia. El diplomático italiano había conseguido el reconocimiento del vaticano por parte de Yugoslavia y fue el primer prelado, después de la Revolución Rusa, en entrar en el Kremlin, para firmar el Tratado de No Proliferación de Armas Nucleares, en 1971.

Los cardenales Wyszynski y Wojtyła son críticos con la política llevada de la ostpolitik vaticana. El cardenal de Cracovia creía que la supuesta apertura hacia el este, podía traer la pérdida de Polonia, la verdadera piedra clave del catolicismo al otro lado del muro. El cardenal Wojtyła estuvo ayudando de forma clandestina a seminaristas checoslovacos, que sufrían una represión muy dura, ordenándolos sacerdotes en Polonia. El primado polaco tuvo en 1975 un duro enfrentamiento con Pablo VI, exigiendo una actitud viril. El cardenal Wojtyła, sirve de puente y amaina la tensión entre sus dos grandes protectores, pero sin dejar de hacerle ver que el occidente consumista no piensa sano por su corrupción, a diferencia de las iglesias jóvenes de los

\footnotetext{
${ }^{36}$ A. RicArdi, Juan Pablo II. La Biografía, San Pablo, Madrid, 2011, p. 188.

${ }^{37}$ S. Glejdura, "La Ostpolitik en el Vaticano", en la Revista Politica Internacional, no 133, Mayo/Junio, Instituto de Estudios Políticos, Madrid, 1974, pp. 203-219.
} 
otros continentes, pobres pero apostólicas ${ }^{38}$. Para Wojtyła la lucha contra el comunismo era una lucha cultural contra la mentira y la muerte, que representaba el comunismo. La persona necesitaba de la libertad para poder seguir su propia decisión, es una unidad que vive en paz, por el respeto de la integridad de sus derechos, no sólo de una parte de ellos. En Polonia el comunismo, según las palabras de Karol Wojtyła "persiguió a todas las personas incómodas para el sistema, como, por ejemplo, a los excombatientes de septiembre de 1939, a los soldados del ejército nacional en Polonia al terminar la Segunda Guerra Mundial o a los intelectuales que no compartían la ideología marxista o nazi. Generalmente se trataba del exterminio físico, pero a veces también de una destrucción moral: se impedía más o menos drásticamente a la persona el ejercicio de sus derechos" ${ }^{\prime 39}$.

\section{CÓNCLAVES PARA LA BÚSQUEDA DE UN PAPA}

El 6 de agosto de 1978, el Papa Pablo VI fallecía dejando un profundo vacío en la Iglesia. Su labor había sido finalizar el Concilio Vaticano II, transformando profundamente el catolicismo. Pablo VI continuó la política de internacionalización iniciada por Pío XII y promovió el nombramiento de 143 cardenales, que por primera vez representarán de forma importante a todos los continentes, visualizando la universalidad de la Iglesia, y dejando de ser una institución exclusivamente italiana. El Papa fallecido había abierto el diálogo ecuménico con el resto de las comunidades cristianas, siempre desde la verdad. Los cardenales querían un italiano con aire pastoral, que reforzarse la relación con la comunidad católica. El cónclave del 26 de agosto de 1978 reunió a 111 cardenales que eligieron al Patriarca de Venecia, Albino Luciani, que tomó el nombre de Juan Pablo I, uniendo los nombres de sus últimos antecesores, que fueron quienes le nombraron obispo y cardenal respectivamente $^{40}$. El nuevo Papa recordaba la bonomía de Juan XXIII, su

\footnotetext{
${ }^{38}$ A. RicARDI, Juan Pablo II. La Biografía, San Pablo, Madrid, 2011, pp. 186-188.

${ }^{39}$ JuAn Pablo II: Memoria e Identidad, La Esfera de los libros, Madrid, 2005, p. 24.

${ }^{40}$ J. Herranz, En las afueras de Jericó: recuerdos de los años con san Josemaría y Juan Pablo II, Rialp, Madrid, 2007, p. 265.
} 
antecesor en el Patriarcado de Venecia. Cómo arzobispo había sido visible su cercanía a los enfermos y a visitar a los sacerdotes de su diócesis, mostrando un perfil pastoral claro, sin que por ello no dejase de ser un intelectual, al doctorarse en la figura de Antonio Rosmini y ser experto en teología negativa.

Sin embargo, el Papa Luciani, el de "la sonrisa" fallecía a los 33 días de su nombramiento, abonando todo tipo de rumores por su temprana muerte. El colegio cardenalicio debía reunirse de nuevo. El 14 de octubre de 1978 volvían a reunirse 111 cardenales para elegir al nuevo pontífice. Según los comentarios de los expertos, la pugna estuvo entre el cardenal de Génova, Giuseppe Siri, que reunía a los cercanos del cardenal Alfredo Ottaviani, y el cardenal de Florencia, Giovanni Benelli, que por su trabajo como sustituto de la Secretaría de Estado, reunía a los "montinianos", como eran llamados los que habían trabajado con Pablo VI, antes de su pontificado. Ante la imposibilidad de ninguno de ellos de conseguir la mayoría necesaria, fue el cardenal de Viena, Franz König, experto en religiones, y pionero del ecumenismo, quién admiraba la clarividencia que el joven Karol Wojtyła tuvo en el concepto de libertad religiosa en el Concilio Vaticano II, quién vio la transversalidad del cardenal con los dos bloques. Su pensamiento social, y su labor en el Concilio lo convertía en un hombre acorde con el pensamiento de los "montinianos", a su vez, su solidez intelectual frente a los totalitarismos, lo convertía en un hombre próximo a los apoyos de Siri.

El 16 de octubre de 1978 el mundo se sorprendía con la proclamación de un Papa no italiano, desde el neerlandes Adriano de Utrecht, preceptor de nuestro Carlos V, ningún otro había llegado a sentarse en la silla de Pedro. Karol Wojtyła adoptaba el nombre de Juan Pablo II, para terminar con el trabajo inconcluso del papa Luciani.

\section{El CARDENAL KAROL WOJTYŁA ES ELEGIDO PAPA CON EL NOMBRE DE JUAN PABLO II}

La elección del Papa Juan Pablo II dio voz a una Iglesia del Silencio que descubría el telón comunista, y dejaba ver martirios, persecuciones, degrada- 
ciones y traiciones. El cardenal Wyszynski invitó al Papa a su patria y recibió la visita papal en Polonia en 1979. Fue la primera visita de un Papa a un país del orbe comunista. Su visita oficial en junio de 1979, unificó a la nación en torno a unos principios ligados con la dignidad humana ${ }^{41}$. Juan Pablo II les habló en su homilía de Varsovia, de historia y cultura, de cómo en 1944 fueron abandonados por los aliados y aplastados por los nazis que devastaron la ciudad, pero en aquellas ruinas quedó la estatura de Cristo llevando la cruz. Polonia descubría a través de sus palabras su identidad y aquella visita tendría consecuencias ${ }^{42}$. El fallecimiento en 1981 del cardenal primado trasladó el liderazgo moral de la Iglesia en Polonia al joven Papa eslavo.

La aportación del Papa Juan Pablo II a la caída del comunismo y a la restauración de las libertades en los países de la Europa del este será determinante. Durante los 27 años de su pontificado, la Iglesia Católica se visualizó de una manera enorme, siendo nombrado en 1994 la persona más influyente del mundo por la revista Time. El pontífice polaco llegará a visitar 127 países y duplicará las relaciones diplomáticas existentes, llegando a 173 países. Su perfil lingüístico, llegará hablar diez idiomas, entender cuatro más y con conocimiento de otras cuatro, le permitirá una gran cercanía con los fieles. $\mathrm{Su}$ carisma con los jóvenes le permitirá afrontar problemas reales de aquella generación, desde la concepción de la persona humana, el amor y el sexo y la relación del trabajo con la dignidad humana. Su protagonismo será determinante en el hundimiento del comunismo, sin que aquello significase un reconocimiento favorable del capitalismo liberal, al que siempre criticará.

\footnotetext{
${ }^{41}$ R, Martín De La Guardia y G. PÉrez, La Europa del Este, de 1945 a nuestros días, Síntesis, Madrid, 1995, p. 166.

${ }^{42}$ G. WeIgel, Juan Pablo II. El final y el principio, Planeta, Barcelona, 2011, P. 116.
} 